\title{
O PERCURSO INTERPRETATIVO DE UM DISCURSO ARGUMENTATIVO
}

\author{
Maria Adélia Ferreira Mauro*
}

\begin{abstract}
RESUMO: O texto descreve o percurso interpretativo de um discurso argumentativo - o artigo assinado da página editorial -, destacando o quadro teórico que orienta essa atividade interpretativa, bem como as estratégias de construção do sentido ai desveladas. Analisa-se, particularmente, a parte introdutória de dois discursos em confronto na página editorial de um jornal paulista, buscando explicitar as operaçōes discursivas que os individuam São discutidas as operaçōes realizadas pelos locutores/enunciadores, identificando-se as escolhas efetuadas no núvel sintático e semântico dos enunciados que configuram essa parte da estrutura argumentativa na qual a relaçāo subjetiva se instaura e o jogo argumentativo se esboça.
\end{abstract}

Palavras-chave: discurso argumentativo, interpretação, estratégias $e$ operações discursivas.

\section{INTRODUÇĀO}

Como interpretar um discurso argumentativo? Com esta pergunta, abre-se um leque de questões a respeito não só da natureza e tipo de discurso que se pretende interpretar, quanto do modo de se efetuar esse percurso interpretativo.

Essas reflexões buscam o apoio e, consequentemente, levam a estabelecer 'a priori' pontos de vista de ordem teórica que se fundam basicamente na vertente da problemática enunciativa, abordada quer pela via da Nova Retórica, quer pela corrente pragmática

(*) Professora do Departamento de Lingūistica, FFLCH/USP. 

argumentativo. Língua e Literatura, $n^{\circ} 23$, p. 79-96, 1997.

(Fuchs, 1985). Se as teorias da argumentação oferecem o suporte teórico para o enfrentamento da questāo do discurso persuasivo em situação, a corrente pragmática oferece suporte para buscar o fundamento (lingüistico e/ou situacional) de certos mecanismos e estratégias discursivas que marcam "os modos de dizer" persuasivos. E ao privilegiar a argumentaçāo (e sua dependência do contexto pragmáticol enquanto estratégia que visa conduzir o interlocutor a uma certa conclusão, põe-se em relevo o pólo interpretativo desse discurso. Não se dicotomiza este do pólo da produção, mas na dialogia que se estabelece mediada pelo texto, privilegia-se aqui o leitor e as pistas de que se utiliza ao percorrer interpretativamente o discurso argumentativo.

Resta pontuar quais aspectos sāo privilegiados nesta situaçāo particular de leitura, desvelando os recortes feitos, os procedimentos utilizados na aproximação do texto e os limites aos quais este percurso interpretativo ele próprio se circunscreve ${ }^{1}$

\section{UM DISCURSO DE NATUREZA ARGUMENTATIVA: O ARTIGO ASSINADO DA PÁGINA EDITORIAL}

O artigo assinado da página editorial caracteriza-se como um discurso de natureza argumentativa que, ao lado do editorial, configura o espaço discursivo conferido à opiniāo, no cenário enunciativo composto por esta pâgina do jornal. Entendendo-se opinião aqui não em sua dimensão contingente e efêmera, mas como força racional capaz de exercer pressão sobre os individuos, instância julgadora a exigir um processo de esclarecimento e formaçāo do próprio público, como diz Chauí (1982). E ao conferir foros de verdade à opiniāo, o discurso que a manifesta procura pela argumentaçāo conduzir um dado ouvinte à ação.

Contrariamente ao discurso de demonstração que se constrói para nāo importa quem (Grize, 1981: 32), o discurso argumenta-

(1) Uma versāo reduzida deste trabalho foi apresentada sob a forma de Comunicaçāo no XI Congresso Internacional de la ALFAL, Canarias (Espanha), julho de 1996 e encaminhado para publicaçāo nos Anais do Congresso. 
tivo implica um processo dialógico: a ação de A sobre B. E segundo Grize (1981), esta açāo pode ser concebida sob dois planos: o do orador (A) e do ouvinte (B). Na dialogia dos planos, A se propōe conduzir B a 're-dizer' o que foi dito e fazer com que B aja em uma dada direção ou, pelo menos, prepará-lo para agir naquela direção. E para que o discurso de $A$ induza $B$ a essa reconstrução proposicional uma série de condiçōes devem ser satisfeitas. Não só condiçōes de coerência discursiva, mas também as condiçōes fornecidas pelo “jogo de imagens" mútuas que se fazem os interlocutores dessa relação dialógica. Essas imagens dialogicamente construidas a partir dos lugares ocupados pelos protagonistas do jogo intersubjetivo envolvem nāo somente conhecimentos como também valores mutuamente partilhados. Vale dizer que se afirma aqui a importância do quadro sócio-cultural em que se insere a argumentaçāo quanto à prevalência dos aspectos ideológicos e afetivos que pervadem esse tipo de discurso. Faz-se explícito, no jogo de interlocução, o componente subjetivo da argumentação.

E para que se escape à influência do arbitrário, do efêmero, da volubilidade que possa marcar um discurso que se constrói sobre o provável - mesmo que este discurso reflita a opiniāo comum de um auditório e se ligue ao quadro de um discurso de natureza pública (Perelman, 1982) - há que se dominar estes fatores de ordem intersubjetiva e fazer emergir pelo próprio discurso, pela força interna da linguagem, o efeito persuasivo decorrente de uma atividade argumentativa racional.

Esta atividade se funda nāo só no método de organizar discursivamente a argumentação, na busca de razões que sustentem as opiniōes que se defendem, mas também na escolha dos valores que vão "informar" as premissas, ou melhor dito, o(s) ponto(s) de partida em que se vai assentar a "demonstraçāo" Este componente lógico da argumentaçāo - modos de raciocinio e esquemas de argumentação - não prescinde do componente ideológico e afetivo que determina, em última instância, a aceitabilidade ou não dos valores expressos pelas premissas. Assim, fatores de ordem lógica e psico-social (afetivos e ideológicos) contribuem para a eficácia do processo argumentativo. 

argumentativo. Lingua e Literatura, $\mathrm{n}^{\circ} 23$, p. 79-96, 1997.

\section{O JOGO DE IMAGENS DISCURSIVAS - A ORDEM DA INTERLOCUÇÃO}

Uma visada da argumentação sob a perspectiva da relação intersubjetiva põe, entre outros aspectos igualmente relevantes, a questão da imagem discursiva dos sujeitos da interlocuçāo. Tomando-se, no caso, o aspecto da construção dessa representação, a partir da posição do agenciador do discurso, tem-se que, ao lado de uma representação do mundo, este agente constrói no próprio ato enunciativo uma imagem discursiva dele próprio. Não se confunde tal imagem, que se constitui na própria atividade discursiva e que é intrinseca ao discurso, com as qualidades morais e externas que provêm da natureza do locutor, deste que responde pela seqüência dos enunciados produzidos, na situação comunicativa que se instaura no momento em que o artigo assinado, na página editorial, se abre à leitura.

Não é que a verificação da coerência entre imagem discursiva e a personalidade real do locutor desse discurso opinativo seja fator de menor grau de importância, só que no processo interpretativo que ora se instaura, há interesse em explicitar sinais e procedimentos discursivos que constróem essa imagem moral e os efeitos desta imagem sobre o ouvinte. Ou melhor, tentar evidenciar quais são esses sinais e procedimentos discursivos que tornam o orador digno de confiança, abrindo caminho à persuasão. Segundo o que afirma Declercq (1992), ao discorrer sobre a natureza da "prova ética" na Retórica aristotélica, a eficácia da argumentação depende estreitamente do dominio que o agente do discurso tem sobre essa imagem ética, pois é transferindo a confiança concedida à sua pessoa para o propósito que defende, que esse agenciador do discurso pode esperar conseguir persuadir seu ouvinte.

A representaçāo ética do agenciador do discurso está estreitamente vinculada à imagem comum partilhada pelo público a respeito dos valores morais e virtudes tidos como dignos de suscitar a confiança dos ouvintes. Assim, a conformidade do agenciador do discurso à essa representação moral que o público faz do que seja um orador digno de confiança traz à tona nāo só as relaçōes dialógicas 
entre os dois planos que constituem a ordem da interlocução, quanto o entrelaçamento dos fatores éticos (o caráter de cada orador) e dos fatores afetivos e ideológicos (as paixões e os valores que mobilizam os ouvintes) no processo persuasivo. O cruzamento dos fatores de ordem subjetiva na argumentação põe em relevo o caráter "sensível” do discurso e evidencia como seu agenciador utiliza a imagem ética em função das expectativas do público ao qual se dirige e como se aproveita do conhecimento de que dispōe sobre as emoçōes e os valores que dominam esse mesmo público, ao jogar com representaçōes que vāo inclinar favoravelmente esse público em direção às premissas que defende.

Esta movimentação, esta atividade discursiva vem de manifestar a presença de um sujeito que vai tecendo o discurso e que pelas estratégias argumentativas que utiliza vai individuando seu "modo de dizer" seu estilo de argumentar, contrapondo-se a outros modos de dizer que convivem e dialogam entre si na mesma página editorial.

Como se apresenta discursivamente essa "persona" diante de seu público? Como essa "persona" representa os comportamentos, as açōes ou situaçōes de forma a provocar a mobilização das paixōes do público? Quais estratégias argumentativas dão conta desse jogo intersubjetivo de imagens que põe em cena valores partilhados pelos atores da persuasão? Quais os valores são realçados e de que maneira o sāo? Como estes fatores de ordem "não-lógica", "não-racional" entram na constituição do processo argumentativo desses artigos da página editorial?

\section{ARGUMENTAÇĀO E ESTRATÉGIA DISCURSIVA}

Essa relação (inter)subjetiva que está na base do discurso argumentativo da página editorial vai sendo estabelecida no processo de construção do sentido desse discurso, mediante as estratégias que ai são utilizadas. Desde que se entenda essa construção de sentidos como um conjunto de operações realizadas no processo de interação discursiva, ou seja, como um conjunto de estratégias de 

argumentativo. Lingua e Literatura, $\mathbf{n}^{\circ}$ 23, p. 79-96, 1997

compreensāo/produçāo. Estratégias estas compreendidas como "uma cadeia de razões daqueles que raciociam no e pelo discurso e portanto realizam inferências a fim de compreender...(Parret, 1988:24)" Sob tal perspectiva, a atividade interpretativa desse discurso opinativo, no caso, do artigo assinado da página editorial, em sendo um processo de raciocínio implica não só pressuposição de valores quanto compartilhamento de propósitos entre quem fala e quem entende. Portanto, esta "racionalidade ligada ao discurso" se exterioriza como um conjunto de operações realizadas no processo de interacão discursiva. Nessa atividade interpretativa, as concepções de estratégia, de racionalidade discursiva, das relaçōes entre a dimensão da produção e da compreensāo do sentido das seqüências discursivas estão fortemente ligadas ao contexto. Sob tal perspectiva, antes que se apontem alguns dados da leitura dos artigos selecionados para análise, é importante que se recorra a alguns indicadores do contexto da página editorial. Tais indicadores permitem circunscrever os limites das unidades discursivas e textuais e estratégias de seus respectivos agenciadores, como também demarcar a ação do agenciador institucional e a "configuração" que faz do espaço discursivo da página editorial.

Do conjunto dos artigos coletados na página de opinião dos jornal O Estado de S. Paulo (1993 a 1996) assinados, respectivamente, por Frei Beto, identificado, ao pé do artigo como escritor, e Dom Lucas Moreira Neves identificado como cardeal arcebispo de Salvador e primaz do Brasil, são dois os textos aqui selecionados para a análise: "O Corpo e o Sangue de Cristo e a bandeira do PT" (FB, 1993) e "Cinco chagas luminosas" (LMN, 1993). Publicados, separadamente, no mesmo espaço discursivo, o artigo de Dom Lucas, no dia 26 de maio e o de Frei Betto, no dia 9 de junho, aproximamse, entretanto, pelo "motivo" que os provocou - a comemoraçāo de Corpus Christi, incluido no calendário do ano civil como feriado nacional e religioso -. E é importante que se note que os articulistas se alternam, nesse espaço discursivo: embora seus artigos apareçam no mesmo dia da semana (quarta-feira), há um intervalo de uma semana entre a contribuicão de um e outro. Assim sendo, há que se considerar nessa "configuração" estabelecida pelo agencia- 
dor institucional, a presença de mais um artigo de Dom Lucas, no dia 2 de junho - Cinco chagas salvadoras - que, recuperando o tema do artigo anterior (o do dia 26 de maio), marca a sua intervenção mais próxima da comemoração da festa religiosa e se antecede, no tempo, ao pronunciamento do Frei Betto. A recuperação dessas informações, a partir do co-texto da página editorial e do contexto situacional, permitem ao leitor estabelecer, ainda que esquematicamente, o cenário enunciativo "armado" pelo locutor institucional, em cujo espaço se instaura o jogo intersubjetivo entre o locutor/ enunciador e seu público-leitor...

A recuperação de tais informações permite ao leitor que assiduamene frequenta o espaço discursivo dessa página de opinião, flagrar o diálogo intertextual instituido pelo jornal, semanalmente. É um jogo intertextual que procura trazer, periodicamente, à presença dos leitores o embate entre pontos de vista que se fundam em valores que são próprios dos "lugares" ocupados por esses agenciadores do discurso, no caso, Frei Beto, um ex-frade dominicano conhecido por seu engajamento político e filiação ao Partido dos Trabalhadores (o PT) e dom Lucas Moreira Neves, um representante da alta hierarquia da Igreja Católica Romana no Brasil. Aqui, as informaçōes extraídas do co-texto da página editorial são complementadas pelas informações buscadas no contexto situacional...

Portanto, co-texto e situação sāo fatores com os quais o jornal "joga” para estabelecer esta relação dialógica entre textos com a finaldade de instaurar, no espaço enunciativo da página editorial, o debate que efetivamente se vem travando no espaço sócio-cultural e político do pais, no momento. $E$ ao fazê-lo, nāo deixa este locutor/ enunciador institucional de criar uma imagem positiva de si próprio enquanto órgão de imprensa, concedendo espaço à divergência, mesmo que esta contrarie a sua linha editorial...

Ao assumir publicamente a divergência e conferir-lhe legitimidade, busca aliar seu discurso em defesa da livre imprensa e o da livre expressāo à sua praxis jornalistica. É uma estratégia que não visa apenas à comunicação, à informação, à intenção de tornar esse debate conhecido do público - leitor... Vai além, pois, a "teatralidade" do colocar em cena o debate tem, entre outras finali- 

argumentativo. Lingua e Literatura, $n^{\circ}$ 23, p. 79-96, 1997.

dades, a de construir uma imagem de credibilidade, de seriedade e, acima de tudo, de coerência com os princípios que defende em relação à função da imprensa numa sociedade democrática. Enfim, uma estratégia que busca a individuaçāo de seu discurso institucional. Um discurso que tem também um evidente objetivo didático pela reiteração periódica que faz, no caso, dos discursos de Frei Beto e Dom Lucas em sua página editorial.

Assim, um duplo contexto vem caracterizar a atividade argumentativa do agenciador do discurso institucional: de um lado, o conjunto das pressuposições e conhecimentos partilhados pelos protagonistas dessa relaçāo interlocutiva - o jornal e o seu públicoleitor -; de outro, a própria discursividade explícita presente nos artigos assinados pelos articulistas.

\section{AS ESTRATÉGIAS DE CONSTRUÇÃO DO SENTIDO}

A explicitaçāo dos procedimentos utilizados pelos locutores/ enunciadores na formulação do título e na organização discursiva dos parágrafos introdutórios pode já possibilitar a apreensão de características que individuam suas práticas argumentativas. Tais procedimentos revelam as escolhas efetuadas ao nivel sintático e semântico dos enunciados que configuram a parte da estrutura argumentativa na qual se realiza o ato de promoção (Osakabe, 1979). É nesta parte do discurso argumentativo que a relaçāo subjetiva se instaura e o jogo argumentativo se esboça, dai a razão de se privilegiar, nesse estudo, a análise das operaçōes discursivas aqui efetuadas.

Prospectivamente, os títulos dos artigos já avançam algumas conclusōes sobre o tema dos discursos, que serāo afirmadas/confirmadas no decorrer da leitura.

Em “O Corpo e o Sangue de Cristo e a bandeira do PT" se adianta a relação que o locutor /enunciador pretende estabelecer entre o planos da Fé (da Religiāo) e da História (da Política). Tal aproximaçāo é lingūisticamente marcada pela seleção de dois sintagmas 
nominais definidos articulados pela conjunçāo 'e' os quais funcionam como instruções para identificar os referentes do discurso.

Não se trata apenas de uma operação de referenciaçāo. A forma sintática de enunciado-titulo permite que se faça uma interpretação pressuposicional da conjunção 'e' que articula ambos os sintagmas. Tal interpretação sinaliza a forma pela qual a argumentação vai se realizar: há a escolha por um procedimento de ligaçāo (Perelman, 1982). A opção por esse procedimento implica a utilização de um esquema argumentativo que aproxima elementos distintos - o Corpo e o Sangue de Cristo/ a bandeira do PT - e permite que se estabeleça entre eles uma solidariedade, visando a sua estruturação enquanto unidade, a despeito da opinião de alguns que consideram tais elementos e valores a eles conjugados como absolutamente separados:

E alguns clérigos, que exercem seu direito de dar opiniōes políticas, censuraram Lula por vincular a bandeira do seu partido ao sangue de Cristo, como se lideres politicos não fossem parte do Corpo de Cristo $e$ estivessem excluidos da redenção universal obtida pelo sangue de Cristo (FB, 1993).

E a interpretação pressuposicional da conjuncão ' $e$ ' pode ser ainda feita em relaçāo à articulaçāo dos núcleos do primeiro sintagma do título - O Corpo e o Sangue de Cristo... -. uma vez que esta interpretação vai encontrar seu fundamento na seqūência discursiva do parágrafo inicial, quando o agente do discurso enuncia sua crença na indivisivel unidade entre e em todos os seres., utilizando esse princípio como norma de julgamento do fato posto em perspectiva no discurso.

Se há uma sinalização no título quanto aos aspectos enunciativos do tema e escolha do esquema argumentativo, este também pode indiciar o tipo de público que, preferencialmente, pode pretender chamar a atenção. No caso, se configura a imagem de um público particular que comunga pressuposições, conhecimentos e valores comuns aos do locutor/enunciador do discurso. Se não um público "especializado" e "fechado" num único universo de crença , 

argumentativo. Lingua e Literatura, $\mathrm{n}^{\circ} 23$, p. 79-96, 1997

tem-se, nessa situação de interlocução, a construção da imagem prévia de um público-leitor que se dispõe a "ouvir" um discurso que se propōe estabelecer uma aproximação entre dominios considerados, por outros segmentos (e até mesmo por ele, provável leitor), como inconciliáveis.

Embora o título do artigo "Cinco Chagas Luminosas" também esteja a sinalizar a destinação desse discurso a um público particular, não nos parece que a imagem desses "auditórios" sejam absolutamente coincidentes em ambas as situações de interlocução. No caso, esse público particular parece adequar-se à imagem prévia de um ouvinte "especializado" uma vez que as pressuposiçōes e conhecimentos, situam-se no dominio do conhecimento teológico. É no interior desse dominio discursivo e a partir dele que os protagonistas da relação intersubjetiva vão se mover... Por outro lado, se o enunciado-título Cinco chagas luminosas - um sintagma nominal quantificado - cumpre a função de identificar claramente o objeto sobre "o qual o discurso fala" seu significado é ainda muito geral, a despeito de seu núcleo vir especificado por um adjetivo (semanticamente incompativel, note-se !). Não é o caso do título do artigo de Frei Beto, que tem um significado bem mais particular. As diferenças na formulação dos títulos estão a indiciar o modo de cada locutor/enunciador interagir com o próprio material lingūistico e o grau de elaboração revelado na sua utilização. Isto significa que pela linguagem o locutor-enunciador "antecipa" a imagem que faz de seu público-leitor. Ao representar uma dada forma de linguagem em seu discurso, revela uma avaliação prévia que faz de seu enunciatário, aproximando-se de suas expectativas... A escolha da forma lingũistica, "seleciona" também o tipo de público...

Voltando a atenção sobre os parágrafos iniciais dos textos, às partes nas quais se realiza o ato de promoçāo, observemos no artigo "O Corpo e o Sangue de Cristo e a bandeira do PT" como o locutor/ enunciador prepara o seu "ouvinte" para que ele siga a sua argumentação. Ausentando da maioria das sentenças-enunciados as marcas pessoais da enunciação, confere a seu discurso uma característica de objetividade, mesmo que, na última seqüência 
discursiva dessa parte, faça referência a - Para nós, cristãos, o sacramento dessa unidade é o Corpo de Cristo-. Nāo se trata do uso de um indice visando atenuar essa ausência de um "tom pessoal" no discurso, uma vez que essa "pessoalidade" já foi estratégicamente retirada de todos os enunciados que precedem essa proposição. $O$ aposto - cristãos - que acompanha o pronome faz com que interpretemos esse 'nós' não como significando a assunção do pensamento coletivo, apenas, mas como um uso argumentativo que reforça a tese da "unidade" posta como conclusāo, no segmento precedente:

Assim, a ciência comprova aquilo que as religiōes orientais, incluindo o judaísmo, matriz do cristianismo, já haviam pressentido: há uma indivisível unidade entre os seres e em todos os seres. Para nós, cristãos, o sacramento dessa unidade é o Corpo de Cristo.

Assim, o locutor-enunciador permite que o seu leitor possa fazer as inferências: se como cristāos assumimos a unidade enquanto um valor, se nós, enquanto grupo, nos identificamos como uma sociedade de irmãos, a norma que deve pautar nossas açōes é a unidade... São estas entāo as inferências que vão dar suporte ao desenvolvimento do raciocinio argumentativo.

"Objetividade" e "consciência de unidade" (e por extensão, consciência comunitária) são os valores que alicerçam essa relação de interlocução. Há um locutor-enunciador que se coloca estratégicamente à margem de sua individualidade e se dirige a um público-leitor genericamente considerado em sua unidade. $O$ valor da unidade, da irmandade se contrapōe à sua negação - qual seja, a atitude de "exclusão" Tanto uma exclusão de ordem individual, mais particular como aquela imposta a Lula - (...) como se lideres politicos não fossem parte do Corpo de Cristo e estivessem excluidos da redenção universal obtida pelo sangue de Cristo - quanto a exclusão social de todos aqueles brasileiros famélicos que a Caravana da Cidadania visitou pelo interior do Pais

Diferentemente, no artigo assinado por Dom Lucas, essa relação de interlocuçāo é marcada desde o inicio pela dêixis de pessoa - eu e você - que caracteriza discursivamente o diálogo entre o 

argumentativo. Lingua e Literatura. $n^{\circ} 23$, p. 79-96, 1997.

pastor e o fiél. O pastor se apresentando como pai (autoridade que ensina, que reinstaura a correta versāo dos fatos, a "verdade" ... ) e amigo (a benevolência e o bom humor com que julga as pequenas faltas de seu "rebanho"), numa estratégia de aproximação, de envolvimento afetivo do ouvinte:

Ironizar gentilmente, sem maldade, ojeito desconfiado de um dos apóstolos, (... ), não creio que seja pecado, nem venial. Você pode até apelidar de "São Tomé" aquele amigo que não acredita logo no que você diz, mas pede provas.

Contrapōem-se aqui dois atos de promoção distintos - um, mais objetivizado, atraindo o seu ouvinte pelo "racional" considerando esse auditório como um todo irmanado, outro, carregado de "pessoalidade" dirigindo-se a cada um de seus ouvintes em particular. Essas estratégias de representaçāo da relação intersubjetiva, que se explicitam no uso de recursos expressivos da língua, estão à serviço não só dos objetivos da argumentaçāo quanto se vinculam aos valores que estão na base desses discursos.

Mais um aspecto pode ser realçado em relaçāo a explicitaçāo discursiva desse contraponto entre "objetividade" e "pessoalidade": é a preferência pelas formas sintáticas das sentenças-enunciados que iniciam o ato de promoção. No artigo de Frei Beto, diferentemente do que se observa no trecho do artigo de Dom Lucas, transcrito acima, a sentença transitiva está expressa na ordem direta e enuncia um fato, uma evidência que é trazida à lembrança do seu interlocutor. $\mathrm{E}$ circunscreve para esse leitor o ponto de partida de sua argumentação - A Igreja Católica celebra amanhā, 10 de junho . a Festa do Corpo de Cristo -: anuncia que é sobre esse fato que vai desenvolver o seu discurso

No artigo "Cinco Chagas Luminosas" a sentença-enunciado inicial, na ordem indireta, não pōe de imediato para o leitor o "motivo" do discurso. Retarda a sua apresentaçāo, para o fìm do parágrafo: ( ... ) o Senhor da Glória ostenta, refulgentes, as cinco chagas da sua Paixão, para sempre gloriosas ( ... ) - preferindo investir no envolvimento do seu leitor. Em sintese, estas duas maneiras de 
iniciar a interaçāo com o "auditório" de forma mais direta e imediata, de um lado, e de um modo mais demorado, de outro, mostra uma adequacāo da forma à intenção argumentativa dos locutoresenunciadores. Tem a ver possivelmente com um apego maior ou menor de ambos os locutores-enunciadores à tradiçāo retórica, às formas mais clássicas ou mais modernas de organizar o plano da argumentaçāo.

Em "O Corpo e o Sangue de Cristo..." a objetivização discursiva pretendida leva o locutor-enunciador a buscar informações que ampliem o conhecimento do fato posto como motivo da interaçāo discursiva. Com isso nāo só se representa como cristão, como um homem que crê, mas também como um cristão que transita, naturalmente, por outros dominios do conhecimento. Este diálogo se manifesta sob a forma do comentário que o locutor-enunciador vai fazendo, mostrando gradativamente para o leitor a oposição entre a razāo e fé; a importância da ciência na comprovaçāo dos dados de fé. Ao ir tecendo tais comentários focaliza nāo só a relevância do tema quanto mostra como a problemática do dogma cristão (proclamado no Credol pode ser discutido como um prolongamento de certos conhecimentos (a Física quântica) e despertar a "curiosidade" de outros campos (a Filosofia racionalista).

Com esta atitude, o locutor-enunciador abre espaço para um diálogo entre universos discursivos diferentes - Teologia, Filosofia e Ciência - e se firma como um locutor-enunciador que tem autoridade para proferir tal discurso, pois é capaz de discutir o tema não se fechando no interior do discurso religioso, mas indo buscar outros discursos produzidos sobre o problema, quer para mostrar a controvérsia, quer para extrair do outro a confirmação da "verdade" do discurso que assume. Ao se representar, sobretudo, como um homem de fé não exclui a razāo e a ciência... E prosseguindo seu raciocinio argumentativo, nos parágrafos subseqūentes, não exclui a fé cristã do seu fundamento histórico. Em sendo um escritor cristão, conoebe um público-leitor que partilha sua convicção, sem perder de vista que há interlocutores que dele divergem e a quem dirige sua critica.

No artigo "Cinco Chagas Luminosas" o discurso se constitui a partir de um diálogo que o locutor-enunciador estabelece com 

argumentativo. Lingua e Literatura, $n^{\circ}$ 23, p. 79-96, 1997.

outros discursos produzidos no interior de uma dada regiāo do discurso religioso - o Antigo e o Novo Testamento a Teologia - É um diálogo apropriador, pois utiliza esses discursos como argumento de autoridade, garantindo a credibilidade de seu próprio discurso. Os recursos utilizados para introduzir o discurso do outro-discurso relatado, o uso das aspas, a referência (entre parênteses...) - são formas que revelam o grau de "incorporação" desses discursos pelo locutor-enunciador e a forma como ele os reutiliza em função de seu objetivo argumentativo, no caso, levar o seu leitor a "compreender" porque as chagas de Cristo são "luminosas tanto quanto dolorosas" estabelecendo uma comparação com "as chagas da Igreja" - os estigmas da divisāo, das perseguiçōes, do pecado e do mal... -. A crença na redençāo final do pecado e da dor é a "norma" mediante a qual o locutor-enunciador "avalia" e pode levar o seu interlocutor a compreender o que se passa no plano terreno... A crença no plano divino e na redenção final "ilumina” o plano da história.

\section{CONCLUSĀO}

O "exercício interpretativo" desses dois artigos permite uma avaliação ainda que provisória do modo escolhido para se efetuar esse percurso.

Um primeiro aspecto que se destaca diz respeito à dialogia que o leitor pode instaurar entre o discurso que emerge da página de opiniāo do jornal e o discurso explícito manifestado pelos artigos assinados. A configuração da página, a aproximação de articulistas de variada tendência todos esses elementos sāo indices de uma atividade argumentativa que identifica uma prática jornalística e permite julgar a coerência da linha editorial adotada pela empresa jornalistica e verificar como o agenciador institucional trabalha a controvérsia em proveito de seus próprios objetivos. Entretanto, nesse exercicio interpretativo não chegamos assim tão longe... Apenas apontamos alguns aspectos do "jogo intertextual” realizado pelo agenciador institucional com o intuito de demarcar os contextos dos artigos examinados, o que já nos oferece a possibilidade de 
visualizar como a "representaçāo da divergência" torna público o debate e concorre para o processo de formação da opiniāo...

Mas para que se compreenda essa função de esclarecimento $e$ formação do público, é importante que se analise nos discursos dos articulistas "convidados" para emitir sua opinião quais são os temas e quais são os aspectos focalizados; como é realizada a problematização desses temas e qual é o fundamento ideológico que marca os diferentes pontos de partida da argumentação. Quando se desce à análise da discursividade manifestada nos artigos, chegase ao desvelamento das estratégias discursivas utilizadas na construção do sentido.

No caso, a análise de como se configura o ato de promoçāo, a identificação das operacōes de seleção no plano sintático e semântico das sentenças-enunciados, leva a constatar como a forma está a serviço dos propósitos argumentativos. A exclusão das marcas de pessoalidade das sentenças-enunciados e o efeito de "objetivização" que causa num discurso, em oposição à explicitação da "pessoalidade", estrategicamente instaurada num outro discurso, estāo a indiciar, no fundo, a presença de dois valores que procedem de opções operadas a partir da pertença a lugares ideologicamente distintos - um, da escolha preferencial pelo valor comunidade, irmandade, unidade; outro, da preferência pelo valor pessoa, consciência individual....

Mas se tal análise leva a explicitaçāo dos valores e lugares especificos que demarcam as fronteiras e as relaçōes existentes entre esses discursos, tais operaçōes discursivas também podem indiciar o procedimento argumentativo que vai ser utilizado na construção do discurso ou até mesmo sinalizar qual o esquema argumentativo que está sendo utilizado. Tais indices permitem que se avancem algumas consideraçōes quanto ao apego maior ou menor de ambos os locutores-enunciadores à tradição retórica, às formas mais clássicas ou mais modernas de organizar o plano da argumentação (Robrieux, 1992). Mais um indicador que contribui para a construção da imagem desse locutor-enunciador, colocando-o, segundo a perspectiva de alguns, ou no grupo dos "conservadores" ou dos "progressistas" que habitam o interior dessa mesma formação discursiva. 

argumentativo. Lingua e Literatura, $n^{\circ} 23$, p. 79-96, 1997.

\section{BIBLIOGRAFIA}

CHAUI, M.H. ( 1989 ). Os intelectuais e a política ( prefácio ). Opiniāo Pública \& Revolucão. São Paulo, EDUSP.

DECLERQ, G. ( 1992 ). L'Art D'Argumenter. Paris, Editions Universitaires. FUCHS, C. (1985). As problemáticas enunciativas: esboço de uma apresentação histórica e crítica. ALFA, 29: 111-129.

GRIZE, J. B. ( 1981). Schématization, répresentation et images. Stratégies Discursives, Lyon, Presses Universitaires de Lyon.

KEMPSON, R. ( 1980 ). Teoria Semântica. Rio de Janeiro, Zahar Editores. OSAKABE, H. ( 1979 ). Argumentação e Linguagem. Sāo Paulo, Kairós. PARRET, H. ( 1980 ). Enunciaçāo e Pragmática. Campinas, Pontes. PERELMAN, CH. \& OLBRECHTS-TYTECA ( 1982 ). Traité de L'Argumentation. Bruxelles, PUB.

ROBRIEUX, J-J. ( 1993 ). Éléments de Rhétorique et D'Argumentation. Paris, Dunod.

ABSTRACT: This essay describes some interpretative procedures of argumentative discourses stressing the theoretical framework which guides the activity of interpretation, as well as the strategies concerned with such activity. Particularly, it analyses the introductory segment of two confronting discourses in the editorial page of some Brazilian newspapers, attempting to point out the discursive operations that characterize these individual discourses as such.

It furthers discusses the operations performed by the speakers, identifying the choices in the syntatical and semantical levels of the propositions that configure this part of the argumentative structure in which the subjective relation establishes itself and the game of argumentation is sketched out.

Keywords: Argumentative speeches, interpretation, strategies and discursive operations. 


\section{ANEXOS}

(fragmentos dos artigos analisados - parágrafos introdutórios)

\section{Fragmento 1}

A Igreja Católica celebra amanhã, 10 de junho,, a Festa do Corpo de Cristo. Intriga a racionalidade moderna esta insistência do dogma cristão na materialidade do conteúdo da fé. No Credo, os cristãos não proclamam "a ressurreição do espirito" e sim a ressurreição da carne. Isso significa que todo o universo, como acentuava Teilhard de Chardim, será gloriosamente resgatado em Deus e que a fé cristã não admite dualismos como o que pretende, mesmo após esta vida, separar matéria e espirito. Ao mergulhar no fascinante mundo da infra-estrutura subatômica a fisica quântica constata que a matéria prima do atómo, como os quarks, é simultaneamente onda e particula. Na esfera mais ínfima de nossa constituição fisica não se pode separar matéria e energia. Toda matéria, dos olhos que lêem este texto ao papel deste jornal, é apenas energia condensada. Assim, a ciência comprova aquilo que as religiōes orientais, incluindo o judaísmo, matriz do cristianismo, jả haviam pressentido: há uma indivisivel unidade entre e em todos os seres. Para nós, cristãos, o sacramento desta unidade é o Corpo de Cristo. (...)

(FREI BETO, O Corpo e o Sangue de Cristo e a Bandeira do PT. O Estado de S. Paulo, 09/06/93, p. A-2).

\section{Fragmento 2}

Ironizar gentilmente, sem maldade, o jeito desconfiado de um dos apóstolos, no conhecido episódio narrado por São João, nāo creio que seja pecado, nem venial. Você pode apelidar até de "Sảo Tomé" aquele amigo que não acredita logo no que você diz, mas pede provas. Reconheçamos, porém, dois méritos àquele que ganhou para sempre a fama de incrédulo. Primeiro: foi ele quem fez a mais bela profissão de fé ao declarar Jesus seu Senhor e Deus (Jó: 20, 28). Segundo: graças a ele ficamos sabendo que, no seu Corpo glorioso, 

argumentativo. Lingua e Literatura, $n^{\circ}$ 23, p. 79-96, 1997.

Jesus Ressuscitado conservou as suas cinco chagas. Grandes teólogos ensinam até que, elevado ao Céu e "sentado à mão direita do Pai”, o Senhor da Glória ostenta, refulgente, nos pés, nas mãos e no lado, as cinco chagas da sua Paixão, para sempre gloriosas, aquelas chagas outrora dolorosas e ignominiosas.

Ora, se, como cremos, as cinco chagas da Igreja, reproduzem e prolongam as do seu Esposo e Senhor, compreende-se que elas sejam, como as de Cristo, chagas luminosas tanto quanto dolorosas. Para compreendê-las melhor, permito-me repassar no espirito essas cinco chagas no Corpo de Cristo. Cada uma delas recebe o seu bálsamo (...).

(DOM LUCAS MOREIRA NEVES. Cinco chagas luminosas. O Estado de S. Paulo, 26/05/93, p. A-2) 